\title{
SPATIAL AND TEMPORAL ANALYSIS OF MONTHLY WATER CONSUMPTION AND LAND SURFACE TEMPERATURE (LST) DERIVED USING LANDSAT 8 AND MODIS DATA
}

\author{
R. Enriquez ${ }^{1}$, M. Rodriguez ${ }^{2}$, A.C. Blanco ${ }^{1}$, I. Estacio ${ }^{1}$, L.R. Depositario ${ }^{3}$ \\ ${ }^{1}$ Department of Geodetic Engineering \& Training Center for Applied Geodesy and Photogrammetry, University of the Philippines \\ Diliman, Quezon City, Philippines - enriquezrovt@adzu.edu.ph, acblanco@up.edu.ph, icestacio@up.edu.ph \\ ${ }^{2}$ Ateneo de Zamboanga University, Zamboanga City, Philippines - rodriguezmars@adzu.edu.ph \\ ${ }^{3}$ Zamboanga City Water District, Zamboanga City, Philippines - lee.depositario@gmail.com
}

\section{Commission IV}

KEY WORDS: Urban Heat Island, Per Capita Water Consumption, NDVI, emissivity, regression analysis

\begin{abstract}
:
Land Surface Temperature (LST) is one of the important factors in monitoring urban climate. Observing the variations of LST can provide a better understanding of the Urban Heat Islands (UHI) phenomenon. The aim of this research is to assess the relationship between the spatial and temporal distribution of LST and water consumption in Zamboanga City for years 2016 and 2017. Data from the city's water district were used to compute for the per capita water consumption (PCWC) of 49 barangays. Landsat 8 LST data with $30 \mathrm{~m}$ spatial resolution were computed using inverse Plank function and other parameters such as vegetation proportion and surface emissivity to assess LST spatially while MODIS Terra data with $1 \mathrm{~km}$ spatial resolution were used to assess LST temporally. Result showed that Landsat LST and PCWC have moderate correlations with p < 0.01: 0.59 and 0.55 for March and April 2016, respectively; 0.49 and 0.56 for March and April 2017, respectively. These indicated that warmer barangays consumed more water. The temporal correlation of the MODIS LST and the computed PCWC equated a $-0.71, \mathrm{p}<0.01$, correlation. This negative correlation indicated that when LST increases, PCWC decreases, which do not directly indicate that the city consumed less water but rather that the supply was less during warmer months. It was evident as water rationing was experienced during the first quarter of 2016 and intensified on April where the highest LST was recorded. Finally, LST was found of good use in assessing the relationship of temperature and water consumption.
\end{abstract}

\section{INTRODUCTION}

Surface temperature is a major role in assessing urban climatology (Voogt and Oke 2003). The increased temperature and the delayed cooling (Nichol 2005; Santamouris, Paraponiaris, and Mihalakakou 2007; Tzavali et al. 2015) in urban systems compared to its surrounding rural region, or widely known as urban heat islands (UHI), have affected the environment and altered urban resources (Yang et al. 2016). UHIs are partially caused by the physical properties of the city's urban landscape (Martin, Baudouin, and Gachon 2015; Tzavali et al. 2015); this includes building density, road network, presence of urban canyons and industrial sites (Tzavali et al. 2015). Also the lack of vegetation in these urban cities reduces its ability to shed excessive heat (T.R Oke 1987). Other variables that influence this nocturnal event includes climate characteristics, presence of water bodies, land usage and latitude and elevation (Tzavali et al. 2015). Though most studies identify the same factors, UHI still varies locally depending on the city size, physiographic features and meteorological conditions (Martin et al., 2015; Tzavali et al., 2015). This reality has caused difficulties in systematizing the definition of a UHI. The difference of temperature among urban areas also refutes any specific threshold to define urban heat (Imhoff, Zhang, Wolfe, $\&$ Bounoua, 2010). Land surface temperature (LST) is a major parameter used to examine urban heat islands in the surface level (Wang 2015) and understanding surface urban heat islands (SUHI) using LST can also help understand and quantify UHI (Weng 2009).

Today, remote sensing has been widely used to assess SUHI with the use of thermal infrared sensors (Wang 2015). LST can be computed using various algorithm like the single-channel (Jiménez-muñoz et al. 2009), mono-window (Qin and Karnieli
2001) and the split-window algorithm (Rozenstein et al. 2014) and is usually correlated factors such as urbanization (Wang 2015), land cover and land use (El-Hattab, S.M., and G.E. 2017), vegetation coverage (Grover and Singh 2015) and other parameters such as topographic position, land-cover diversity, building volume per area, orientation and anthropogenic heat release (Voogt and Oke 2003).

Previous studies on UHI, SUHI, LST and water consumption found that with each Fahrenheit increase in nighttime temperature, estimated a rise in water consumption of singlefamily residences by $3.8 \%$ (Guhathakurta and Gober 2007) while another study recorded an increase of $1.4 \%$ (Aggarwal, Guhathakurta, Grossman-Clarke and Lathey 2012). Other found that LST caused water consumption to increase in warm months (Alavipanah, Haashemi, Kazemzadeh-zow, Bloorani and Asadolah 2016). The evaluation between UHI, SUHI and LST and water consumption has been somehow less explored though these studies showed that LST and UHI can be of great use to assess the effect of temperature to water consumption.

\subsection{Objectives}

This paper aims to assess the general relationship between the temporal and spatial distribution of Land Surface Temperature and water consumption in Zamboanga City for years 2016 and 2017. To achieve this, the following specific objectives have been identified:

1. Derive LST from acquired Landsat 8 Thermal Infrared Sensor (TIRS) and Moderate Resolution Imaging Spectroradiometer (MODIS) Terra images.

2. Compute for monthly Per Capita Water Consumption (PCWC) per barangay 
3. Correlate the MODIS LST with PCWC temporally and the Landsat 8 LST with PCWC spatially.

\subsection{Study Area}

Zamboanga City, situated on the southwestern tip of the Zamboanga Peninsula, is an independent, chartered and a $1^{\text {st }}$ class highly urbanized area in the region. It is bounded by Zamboanga del Norte and Zamboanga Sibugay on the north, Sulu Sea on the west, Moro Gulf on the east and on the south by the Celebes Sea (Figure 1). The city is the $6^{\text {th }}$ most populous having a recorded population of 861,799 last 2015 census and $3^{\text {rd }}$ largest city in the Philippines with a total land area of $1,483.3849$ square kilometers.

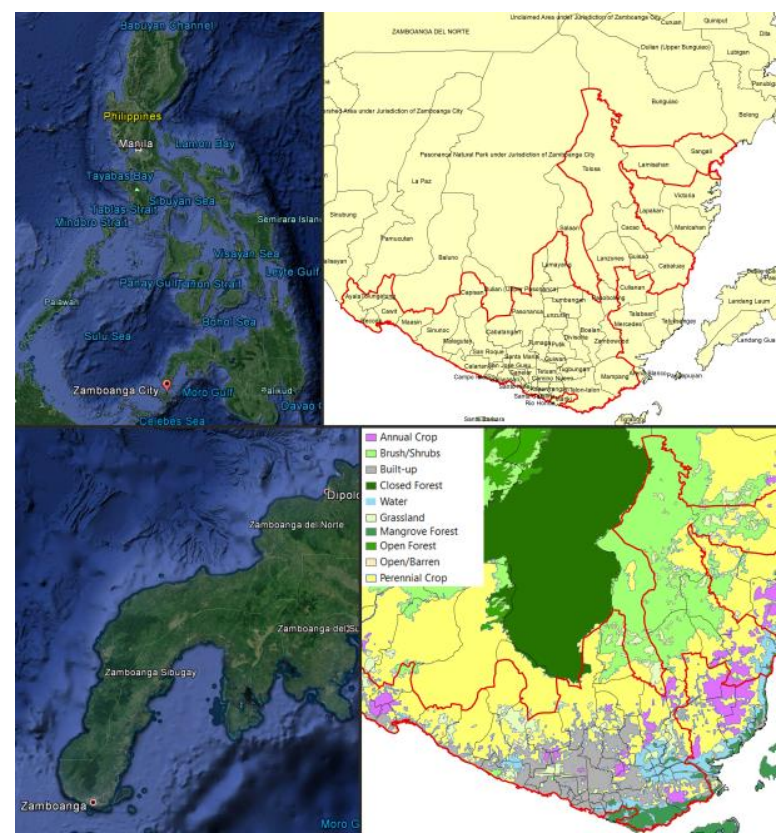

Figure 1. Google Earth image showing location of Zamboanga City (left images), the 49 barangays (right images) covered in the study area (red polygon) and land cover map from the National Mapping and Resource Information Authority (bottom right). Barangay boundary data is from the Philippine Statistics Authority boundary.

Climate in the city falls under the Type III based on the Modified Coronas Classification. The city is located outside the typhoon belt and rarely experience typhoons but is located within one of Mindanao's high-risk zones and is considered one of the most vulnerable cities to the effects of climate change. The Manila Observatory (2016) projected an increase in temperature by $2.1^{\circ} \mathrm{C}$ in 2050 and in contrast a decrease in precipitation rate at $0.6 \%$ by 2025 and $-5.2 \%$ by 2050 .

Zamboanga City Water District (ZCWD) supplies water to fifty six (56) out of ninety eight (98) barangays in the city. Forty nine (49) of which are included in the study as shown in Figure 1.

\section{METHODOLOGY}

The methodology was divided into three parts - per capita water consumption computation, land surface temperature processing, and the linear regression analysis.

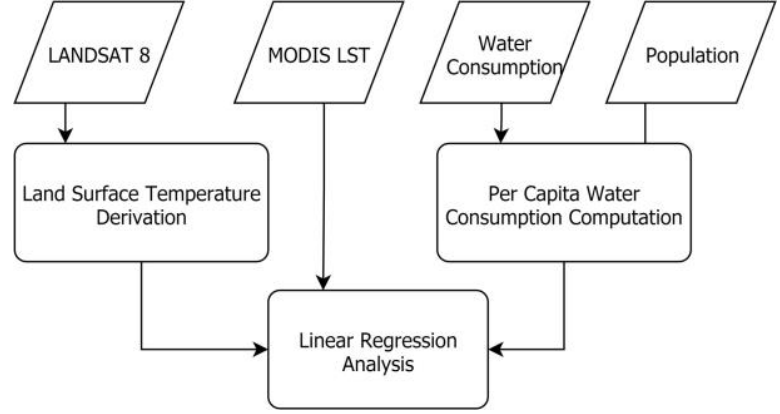

Figure 2. General workflow of the methodology of the research

\subsection{PCWC Computation}

Per Capita Water Consumption (PCWC) was computed by dividing the total water consumption by the total population for each barangay using Eq. (1):

$$
P C W C=\frac{T_{W C}}{T_{P o p}}
$$

where $\quad T_{W C}=$ Total water consumption

$T_{\text {Pop }}=$ Total population

Data from the ZCWD and the 2015 population data from Philippine Statistics Authority (PSA) were used to compute for the PCWC of the 49 barangays.

\subsection{LST Processing}

Landsat 8 Thermal Infrared Sensor (TIRS) data with 30m resolution was used to analyze LST spatially. This TIRS data were converted from Digital Number (DN) to Top of Atmosphere (ToA) spectral radiance using the radiance scaling factors found in the metadata using the equation below:

where:

$$
L_{\lambda}=M_{L} Q_{c a l}+A_{L}
$$

$L_{\lambda}=$ TOA spectral radiance (Watts $\left./\left(\mathrm{m}^{2} * \mathrm{Srad} * \mu \mathrm{m}\right)\right)$

$M_{L}=$ Band-specific multiplicative rescaling factor from the metadata (RADIANCE_MULT_BAND_x, where $\mathrm{x}$ is the band number)

$Q_{c a l}=$ Quantized and calibrated standard product pixel values (DN)

$A_{L}=$ Band-specific additive rescaling factor from the metadata (RADIANCE_ADD_BAND_x, where $\mathrm{x}$ is the band number)

TOA spectral radiance was then converted to brightness temperature in degree Celsius using the inverse Plank function below:

$$
B T=\frac{K_{2}}{\ln \left(\frac{K_{1}}{L_{\lambda}}+1\right)}-273.15
$$

where:

$B T=$ Top of atmosphere brightness temperature $\left({ }^{\circ} \mathrm{C}\right)$ $L_{\lambda}=$ TOA spectral radiance $\left(\right.$ Watts $\left./\left(\mathrm{m}^{2} * \mathrm{~s}_{\mathrm{rad}} * \mu \mathrm{m}\right)\right)$

$K_{1}=$ Band-specific thermal conversion constant from the metadata (K1_CONSTANT_BAND_x, where $\mathrm{x}$ is the thermal band number)

$K_{2}=$ Band-specific thermal conversion constant from the metadata (K2_CONSTANT_BAND_x, where $\mathrm{x}$ is the thermal band number) 
To include in the computation of LST the surfaces' ability to transmit thermal energy to the atmosphere, Land Surface Emissivity (LSE) was computed. First, a Normalized Difference Vegetation Index (NDVI) was derived using near infrared and red bands (Equation 4) to compute for the proportional vegetation $(\mathrm{PV})$ or the estimate of each land cover type for an area.

$$
N D V I=\frac{\rho_{N I R}-\rho_{R E D}}{\rho_{N I R}+\rho_{R E D}}
$$

where:

$\rho_{N I R}=$ spectral reflectance measurements acquired in the near-infrared regions

$\rho_{R E D}=$ spectral reflectance measurements acquired in the red (visible) regions

For global conditions, NDVI values less than 0.2 were considered as bare soil or man-made materials, while NDVI values greater than 0.5 were considered as pure vegetation pixels. If the NDVI values were between 0.2 and 0.5 , the equation (Sobrino, Jiménez-Muñoz, and Paolini 2004) below was used to compute for PV:

$$
P_{V}=\left(\frac{N D V I-0.2}{0.5-0.2}\right)^{2}
$$

Since LSE depends on vegetation cover and surface roughness, the PV threshold was then used to estimate LSE. PV values less than 0 are classified as water and the average LSE is 0.991 , while $\mathrm{PV}$ values from 0 to 0.2 are classified as soil with an average LSE value of 0.966 . For PV values between 0.2 and 0.5 , the land cover is considered to be a mixture of soil and vegetation cover and equation 6 was used to compute for LSE. Lastly, PV values greater than 0.5 are considered as vegetation cover with an average LSE value of 0.973 .

where:

$$
\varepsilon_{\lambda}=\varepsilon_{v \lambda} P_{v}+\varepsilon_{s \lambda}\left(1-P_{v}\right)+C_{\lambda}
$$

$\varepsilon_{\lambda}=$ land surface emissivity

$\varepsilon_{v \lambda}=$ vegetation emissivity

$\varepsilon_{s \lambda}=$ soil emissivity

$C_{\lambda}=$ surface roughness which is the constant value of 0.005

Finally the LST was computed using the brightness temperature and the LSE shown in the equation below:

$$
T=\frac{B T}{\left(1+\left(\left(\frac{\lambda B T}{\rho}\right) \ln \varepsilon \lambda\right)\right)}
$$

where:

$$
\begin{aligned}
& T=\text { LST in degree Celsius } \\
& \lambda=\text { average wavelength of band } 10 \text { which is } 10.89 \\
& B T=\text { computed brightness temperature } \\
& \varepsilon \lambda=\text { land surface emissivity } \\
& \rho=(h * c) / \sigma, \text { which is equal to } 1.438 \times 1 \quad 0-2 \mathrm{mK}
\end{aligned}
$$

To observe LST temporally, Moderate Resolution Imaging Spectroradiometer (MODIS) Terra data were used. Average monthly LST from 2016-2017 were acquired from the daily Land Surface Temperature and Emissivity (LST\&E) provided by the MOD11 product with $1 \mathrm{~km}$ spatial resolution.

\subsection{Linear Regression}

Linear regression analyses were performed to evaluate the relationship between LST and PCWC. To observe the regression spatially, LST for the months of April and March were correlated with the computed PCWC per barangay. On the other hand, to temporally observe the regression, monthly mean LST of the entire 49 barangays were correlated to the computed monthly PCWC of the 49 barangays from January of 2016 to December of 2017.

\section{RESULTS AND DISCUSSION}

\subsection{Spatial analysis of LST and PCWC}

Months April and March where observed for both 2016 and 2017 as the highest LSTs were recorded during these months. The Landsat- 8 derived LST and PCWC data for each barangay during March and April 2016 are presented in figure 3 and 4 respectively. It was clear that the concentration of water consumption in the city during the two warm months was heavily in and near the town area. The same can be said for the LST, where higher LSTs were recorded near the town area. This is supported by the moderately strong correlation obtained between LST and the distance (centroid to centroid) of each barangay from the city center with an $\mathrm{R}$ of $-0.7693, \mathrm{p}<0.01$, for the month of March and an R of $-0.6848, p<0.01$, for the month of April. The acquired negative correlations indicated that as the distance from the town center increases the recorded LST decreases. This is partly due to the fact that, in Zamboanga City, urban development decreases as distance from the city center increases.

The highest recorded LST belonged to barangays Zone IV, Zone III and Zone II while the lowest was recorded in barangay Mampang. The same analyses can be set looking into LST where warmer barangays were located within and near the center of the city, with Zone II acquiring the highest LST followed by Zone I and IV for the month of April. Barangay Tetuan acquired the highest LST for the month of March followed by Zone I and II. Meanwhile the lowest LST was recorded in barangay Lamisahan for the month of March and barangay Tulungatung for April.

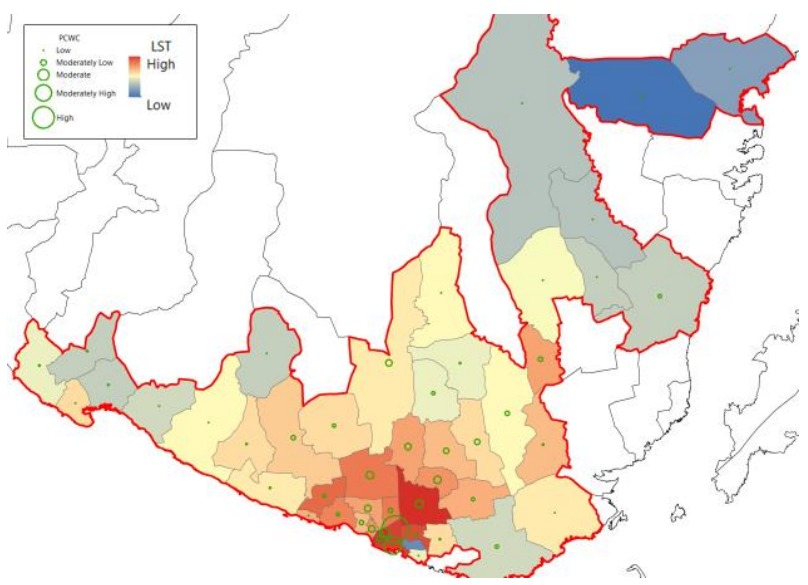

Figure 3. Spatial variation of barangay-averaged LST and PCWC data of the 49 barangays for March 2016 


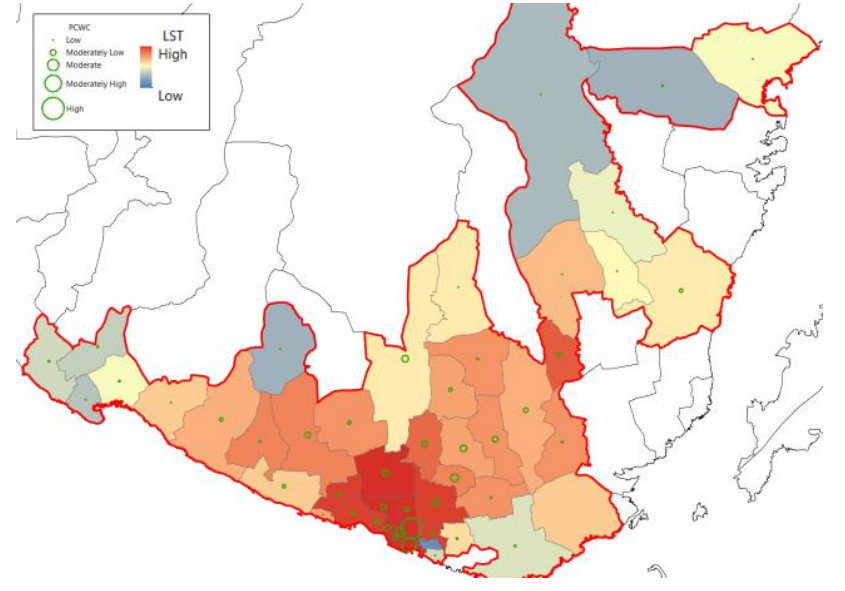

Figure 4. Spatial variation of barangay-averaged LST and PCWC data of the 49 barangays for April 2016

The LST and PCWC regression showed moderate correlation for the month of March with an $\mathrm{R}$ of $0.59, \mathrm{p}<0.01$ and an $\mathrm{R}^{2}$ of 0.35 as shown in Figure 5, while the month of April acquired an $\mathrm{R}$ of $0.55, \mathrm{p}<0.01$ and an $\mathrm{R}^{2}$ of 0.3 (Figure 6).

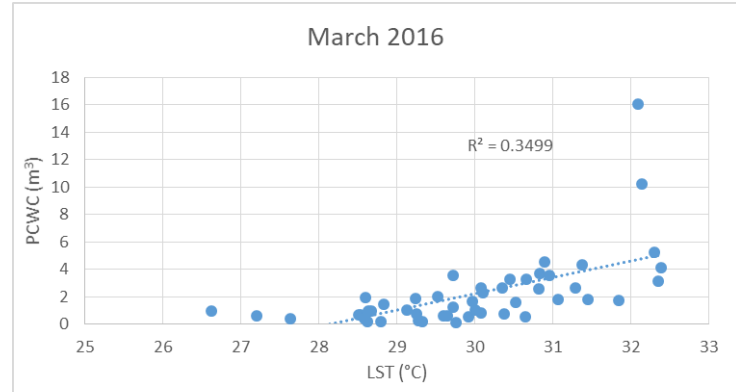

Figure 5. Correlation of LST and PCWC for the month of March, 2016

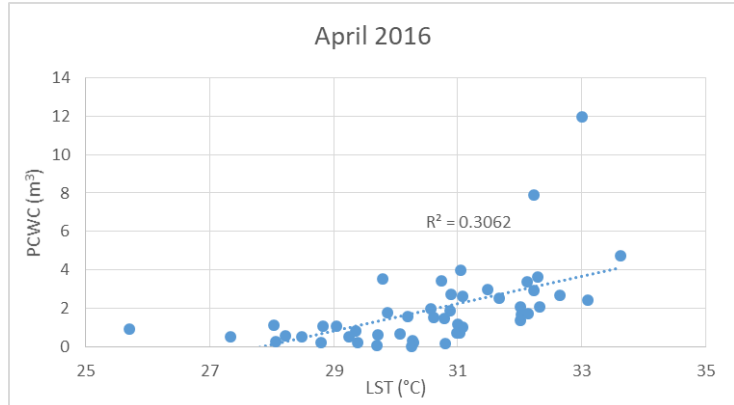

Figure 6. Correlation of LST and PCWC for the month of April, 2016

The same scenario was evident during 2017 for the months of March and April. LST and PCWC data, presented in figure 7 and 8, showed that the concentration of LST and PCWC was heavy in the city center and gradually reduces to farther barangays, which is also supported by the moderately strong correlation acquired from LST and the distance (centroid to centroid) of each barangay from the city center. March acquired an $\mathrm{R}$ of $0.6564, p<0.01$ and an $\mathrm{R}$ of $-0.8303, \mathrm{p}<0.01$ for the month of April. This can be attributed to the socio-economic aspect of each area as the recorded barangays with high LST and PCWC are mostly urban and commercial region (Figure 1).
The highest recorded PCWC were the same with the previous year while the lowest was recorded on barangay Guisao. Zone II, III and IV recorded the highest LST for the month of April while barangays Zone I, IV and Baliwasan for March. Barangay Cawit and Lanzones recorded the lowest LST for April and March respectively.

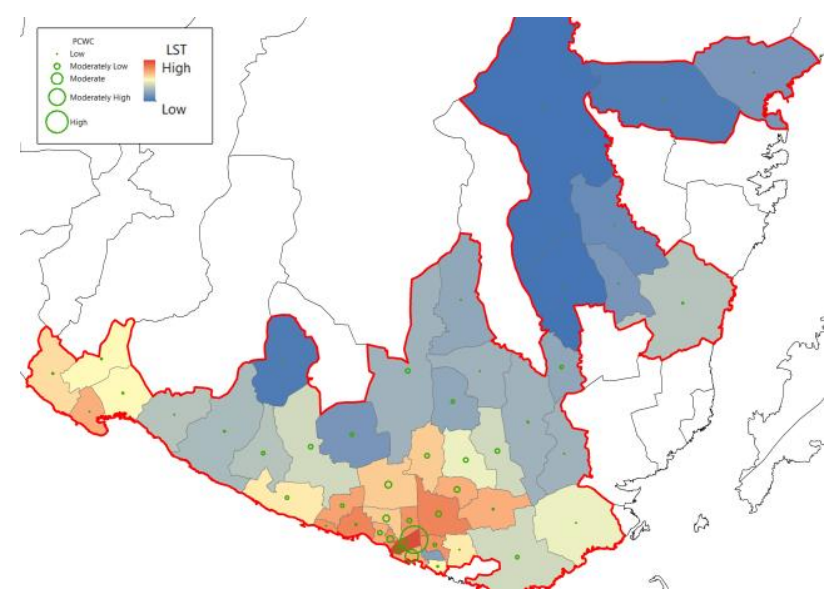

Figure 7. Spatial variation of barangay-averaged LST and PCWC data of the 49 barangays for March 2017

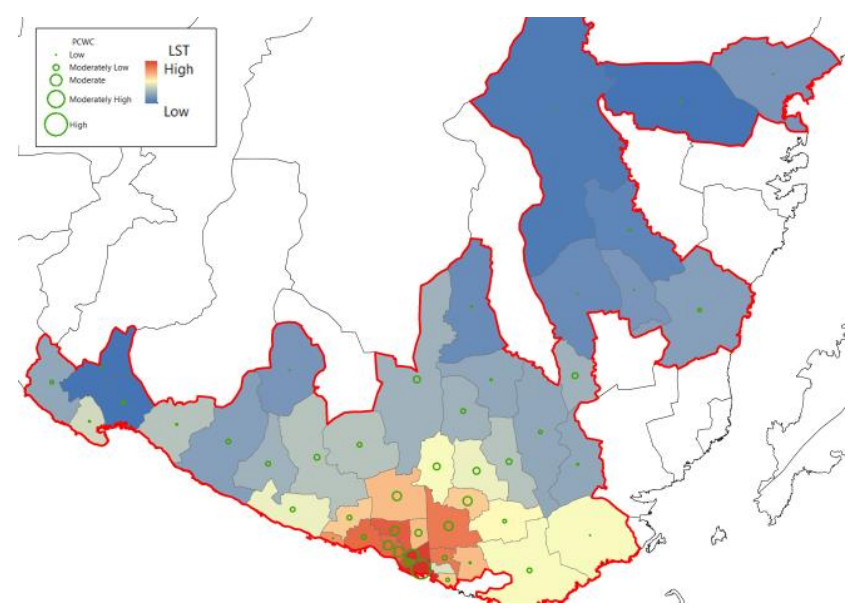

Figure 8. Spatial variation of barangay-averaged LST and PCWC data of the 49 barangays for April 2017

Moderate correlation were also acquired for the months of March and April with an R of 0.49 and 0.56 , p <0.01, respectively. An $\mathrm{R}^{2}$ of 0.24 was acquired for the month of March and 0.31 for the month of April as shown in figure 9 and 10 .

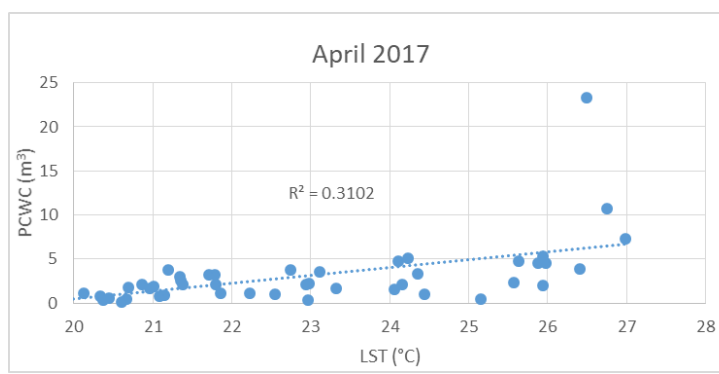

Figure 9. Correlation of LST and PCWC for the month of March, 2017 


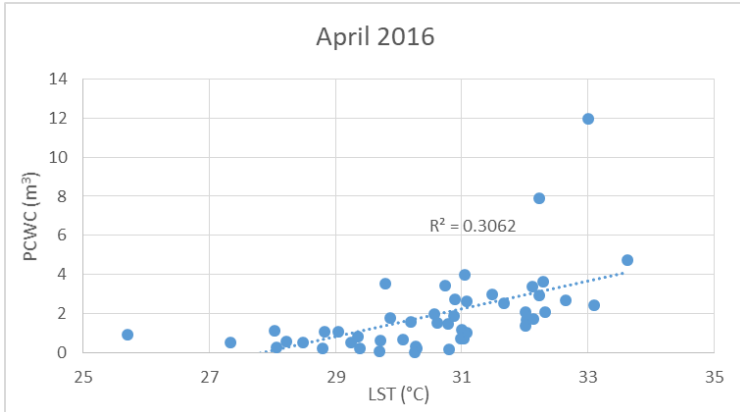

Figure 10. Correlation of LST and PCWC for the month of April, 2017

The positive correlation attained for all months indicated that when the LST values rise the PCWC rates also tend to increase. It was also obvious that April and March were warmer during the year 2016 compared to 2017. It was apparent as an El Niño was experienced during the first quarter of 2016 and intensified on April where the highest LST was recorded.

\subsection{Temporal analysis of LST and PCWC}

The LST derived from the MODIS data revealed that the highest monthly mean LST occurred in April 2016 (Figure 11). The recorded $34.5^{\circ} \mathrm{C}$ was relatively higher compared to the 2016-17 mean average of $29.9^{\circ} \mathrm{C}$, while the lowest recorded mean LST was in June 2017.

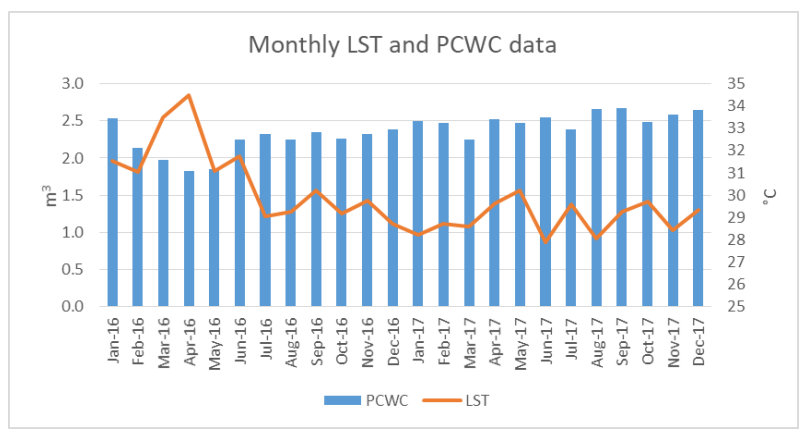

Figure 11. Monthly LST derived from MODIS and computed monthly PCWC data for the entire 49 barangays

However, same month of April 2016 tallied the lowest water consumption with a computed PCWC of $1.83 \mathrm{~m}^{3}$ or 1,830 liters compared to the 2016-17 monthly average of $2.36 \mathrm{~m}^{3}$ or 2,360 liters, while the highest PCWC was $2.67 \mathrm{~m}^{3}$ of September 2017.

Figure 11 revealed that monthly PCWC was moderately contrasting with the monthly mean LST values. This was evident as the correlation between the monthly LST and PCWC produced a negative value. The acquired $\mathrm{R}$ of $-0.71, \mathrm{p}<0.01$, and an $\mathrm{R}^{2}$ of 0.5085 (Figure 12), means that when the LST rises, the PCWC data decreases or the other way around.

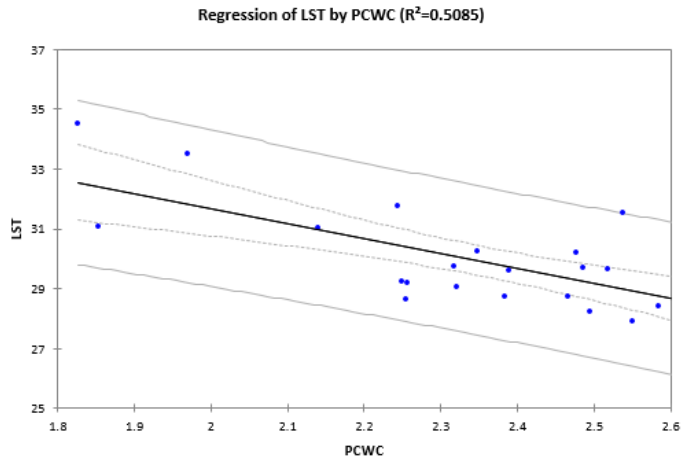

Figure 12. Correlation of monthly mean LST derived from MODIS and monthly computed PCWC

This negative correlation implied that during the years 2016 and 2017, when LST values were high, the water consumption was low, and vice versa. This does not directly suggest that the water demand during warmer months were lower compared to cooler months but rather that the supply of water during warmer months were lesser. This was evident during the first quarter of 2016 as water rationing was experienced throughout the city due to the El Niño.

\section{CONCLUSION}

Land surface temperature and per capita water consumption was used to assess the general relationship between water consumption and surface temperature of 49 adjacent barangays in Zamboanga City for years 2016 and 2017. Zamboanga City Water District's and Philippine Statistics Authority's data were used to compute for the per capita water consumption trend. Using Landsat 8 TIRS data, the PCWC-LST trend was assessed spatially while MODIS Terra data were used to assess the PCWC-LST trend temporally.

Spatial comparison of LST and PCWC showed that barangays that recorded high LST also recorded high PCWC. Therefore, warmer barangays are expected to have higher water consumption and higher demand for water. As the spatial analysis of LST and PCWC showed the effect of LST in the demand and/or consumption of water, the temporal analysis of LST and PCWC showed the effect of temperature in the supply of water in the area.

For more accurate assessments of land surface temperature and water consumption, satellite images with better temporal and spatial resolution can be used. Also, socio-economic data can further be used to explain the different PCWC patterns of each barangay.

Finally, the use of remotely sensed derived land surface temperature can be of great use to assess the spatio-temporal relationship of surface temperature and water consumption.

\section{ACKNOWLEDGEMENTS}

This work is primarily funded by the Philippine Council for Industry, Energy, and Emerging Technology Research and Development-Department of Science and Technology (PCIEERD-DOST) through the project Geospatial Assessment and Modelling of Urban Heat Islands in Philippine Cities (Project GUHeat), Project No. 2048, 2019. 


\section{REFERENCE}

Aggarwal, Rimjhim M., Subhrajit Guhathakurta, Susanne Grossman-Clarke, and Vasudha Lathey. 2012. "How Do Variations in Urban Heat Islands in Space and Time Influence Household Water Use? The Case of Phoenix, Arizona." Water Resources Research 48(6): 1-13.

Alavipanah, Seyed Kazem et al. 2016. "Remotely Sensed Survey of Land Surface Temperature (LST) for Evaluation of Monthly Changes of Water Consumption." GSTF Journal on Agricultural Engineering (JAE) 1(1): 81-85. http://dl6.globalstf.org/index.php/jae/article/viewFile/83/ 82

El-Hattab, M., Amany S.M., and Lamia G.E. 2017. "Monitoring and Assessment of Urban Heat Islands over the Southern Region of Cairo Governorate, Egypt." Egyptian Journal of Remote Sensing and Space Science 21(3): 311-23. https://doi.org/10.1016/j.ejrs.2017.08.008.

Grover, Aakriti, and Ram Singh. 2015. "Analysis of Urban Heat Island (UHI) in Relation to Normalized Difference Vegetation Index (NDVI): A Comparative Study of Delhi and Mumbai." Environments 2(2): 125-38. http://www.mdpi.com/2076-3298/2/2/125/.

Guhathakurta, Subhrajit, and Patricia Gober. 2007. "The Impact of the Phoenix Urban Heat Island on Residential Water Use." Journal of the American Planning Association 73(3): 317-29.

Jiménez-muñoz, Juan C et al. 2009. "Revision of the SingleChannel Algorithm for Land Surface Temperature Retrieval From Landsat Thermal-Infrared Data." 47(1): 339-49.

Martin, Philippe, Yves Baudouin, and Philippe Gachon. 2015. "An Alternative Method to Characterize the Surface Urban Heat Island." International Journal of Biometeorology 59(7): 849-61.

Nichol, Janet. 2005. "Remote Sensing of Urban Heat Islands by Day and Night." Photogrammetric Engineering \&
Remote Sensing 71(5): 613-21.

http://openurl.ingenta.com/content/xref?genre=article\&is $\mathrm{sn}=0099-1112 \&$ volume $=71 \&$ issue $=5 \&$ spage $=613$.

Qin, Z, and A Karnieli. 2001. "A Mono-Window Algorithm for Retrieving and Surface Temperature from Landsat TM Data and Its Application to the Israel-Egypt Border." 22(18): 3719-46.

Rozenstein, Offer, Zhihao Qin, Yevgeny Derimian, and Arnon Karnieli. 2014. "Derivation of Land Surface Temperature for Landsat-8 TIRS Using a Split Window Algorithm." : 5768-80.

Santamouris, M., K. Paraponiaris, and G. Mihalakakou. 2007. "Estimating the Ecological Footprint of the Heat Island Effect over Athens, Greece." Climatic Change.

Sobrino, José A., Juan C. Jiménez-Muñoz, and Leonardo Paolini. 2004. "Land Surface Temperature Retrieval from LANDSAT TM 5." Remote Sensing of Environment.

T.R Oke. 1987. "Boundary-Layer Climates Second Edition." In Boundary-Layer Climates Second Edition, , 6-7.

Tzavali, Anna et al. 2015. "Urban Heat Island Intensity: A Literature Review." Fresenius Environmental Bulletin 24(12B): 4535-54.

Voogt, J. A., and T. R. Oke. 2003. "Thermal Remote Sensing of Urban Climates." Remote Sensing of Environment 86(3): 370-84.

Wang, Minjie. 2015. "Characterization of Surface Urban Heat Island in the Greater Toronto Area Using Thermal Infrared Satellite Imagery By."

Weng, Qihao. 2009. "ISPRS Journal of Photogrammetry and Remote Sensing Thermal Infrared Remote Sensing for Urban Climate and Environmental Studies : Methods Applications, and Trends." ISPRS Journal of Photogrammetry and Remote Sensing 64(4): 335-44. http://dx.doi.org/10.1016/j.isprsjprs.2009.03.007.

Yang, Li, Feng Qian, De Xuan Song, and Ke Jia Zheng. 2016. "Research on Urban Heat-Island Effect." Procedia Engineering 169: 11-18. http://dx.doi.org/10.1016/j.proeng.2016.10.002. 